\title{
A prospective analysis of the risk factors and the perinatal outcome of preterm labour
}

\author{
Sunitha Mary Mathew ${ }^{1 *}$, Ajay Kumar ${ }^{2}$
}

\begin{abstract}
${ }^{1}$ Department of Obstetrics and Gynecology, Believers Church Medical College Hospital, Tiruvalla, Kerala, India
${ }^{2}$ Department of Obstetrics and Gynecology, Government Medical College, Kottayam, Kerala, India
\end{abstract}

Received: 01 November 2018

Accepted: 19 November 2018

\section{*Correspondence:}

Dr. Sunitha Mary Mathew,

E-mail: drsunithammathew@gmail.com

Copyright: (C) the author(s), publisher and licensee Medip Academy. This is an open-access article distributed under the terms of the Creative Commons Attribution Non-Commercial License, which permits unrestricted non-commercial use, distribution, and reproduction in any medium, provided the original work is properly cited.

\begin{abstract}
Background: Preterm labour is a challenging complication encountered by obstetricians. The dictum prevention is better than cure well applies for preterm labour also, hence the importance of knowing the risk factors. Infection is one treatable, thus preventable risk factor.

Methods: Prospective cohort study involving 75 antenatals at gestational age from 28 to $36+6$ weeks. After getting clearance from institutional ethical committee detailed history including history of UTI, excessive vaginal discharge, previous abortions and previous preterm labour and medical complications were collected. Two doses of injection Betamethasone $12 \mathrm{mg} 24$ hours apart were given for all patients. High vaginal swab was taken from all subjects and results analysed. Neonates are then followed up till discharge.

Results: The incidences were higher in primigravidas compared to multiparas. Late preterms (34-36+6 weeks) were the majority in the group. PPROM was the major cause for late preterm births, this was followed by UTI and vaginal infections. Among the high vaginal swab $30.7 \%$ were culture positive. E Coli was the most common organism isolated followed by Staphylococcus Aureus, Klebsiella, and MRSA. Hyperbilirubinemia was the most common neonatal complication. Out of 7 neonatal deaths 6 were due to RDS and one was extremely preterm newborn. Women who delivered at least 24 hours after initiation of steroid were considered steroid covered group. Steroid covered group had lesser incidence of RDS with $\mathrm{P}$ value of 0.001 which was statistically significant.

Conclusions: UTI and vaginal infections were major risk factors for preterm labour and should be tackled antenatally. High vaginal swab should be taken for threatened preterm labour especially early preterm. Betamethasone administration causes a definite reduction in the incidence of RDS. Induce PPROM after 36 weeks to reduce late preterm complications provided there is no chorioamnionitis.
\end{abstract}

Keywords: Antenatal steroids, Early preterm, High vaginal swab, Late preterm, Steroid covered

\section{INTRODUCTION}

Preterm labour is a very important obstetric complication, as it has both short term neonatal and long-term problems. It is defined as onset of labour prior to 37 completed weeks of gestation. Preterm delivery affects one in ten births $(11 \%)$ and even greater in developing countries and causes $40-75 \%$ of neonatal deaths. ${ }^{1}$ Two major factors have contributed to the rise in preterm delivery rate: 1) The dramatic increase in multiple births from assisted reproduction techniques; 2) obstetric interventions at early gestations for obstetric complications. ${ }^{2}$ The dream of every woman is to deliver a healthy and mature baby capable of adapting satisfactorily to extra uterine life. For prevention it is important to identify the high-risk factors for preterm labour. ${ }^{3}$ The causes of preterm labour can be maternal, fetal, placental or idiopathic. 
Preterm infants not only suffer the immediate complications but also have long term sequelae such as neurodevelopmental disability. ${ }^{4}$ Recently late preterm birth and its morbidity has gained importance. ${ }^{5}$ Significant progress has been made in the care of preterm infants, but not so in reducing the prevalence of preterm births.

Though tremendous strides have been made in keeping preterm infants alive, there has been less success in reducing the long-term handicap rate among the survivors. The economic consequences of preterm birth that reach beyond new born period into infancy, adolescence, and adulthood is enormous when the effect of adult disease associated with prematurity such as hypertension and diabetes are considered.

Hence there is a time felt need to ascertain the causes and outcome of preterm labour and the strategies to prevent preterm births. This study emphasizes on the causes and outcome of preterm labour in a tertiary care Medical College in Kerala.

The aim of the study is to identify the risk factors of preterm labour; to identify the role of infection in preterm labour; to find out the most common organism causing vaginal infection and to plan prophylactic antibiotics accordingly; to study neonatal morbidity and mortality of preterm labour in present institution; to study the effect of antenatal steroids in prevention of RDS and to find the survival rate at various gestational age.

\section{METHODS}

This was a prospective Cohort study conducted at Government Medical College Hospital, Kottayam for a period of 1 year, after getting approval from ethical committee. Patients were included after proper counselling and informed consent.

It was a prospective cohort study. 75 antenatal women at gestational age 28 to $36+6$ weeks in true labour pains were taken as cases and patients and their babies were followed up till discharge.

\section{Inclusion criteria}

- Antenatals at 28 to $36+6$ weeks with documented preterm labour, as define by ACOG (1997) criteria.

- $\geq 4$ contractions in 20 minutes or $\geq 8$ in 60 minutes plus progressive changes in cervix.

- Cervical dilatation $>1 \mathrm{~cm}$.

- $\quad$ Effacement $>80 \%$.

- $\quad$ Singleton pregnancy

- No gross congenital anomalies or uterine anomalies.

\section{Exclusion criteria}

- $\quad$ Pregnancy less than 28 weeks and above 37 weeks.
- Those induced for medical indications

- Preterm CS.

\section{Data collection method}

Following admission detailed history including history of UTI, vaginal discharge, bleeding PV, previous abortions, preterm births were entered in the proforma. This was followed by examination to confirm true labour and investigations including high vaginal swab. Injection betamethasone two doses 24 hours apart were given to all and those who delivered at least 24 hours after the first dose were considered as steroid covered group and those not satisfying this were included in the steroid uncovered group. Neonates were followed up in NICU until discharge or death.

\section{Definitions}

PPROM: Rupture of fetal membranes before the onset of spontaneous uterine activity prior to 37 weeks.

Steroid covered group: Those who deliver at least 24 hours after initiation of steroid therapy.

Neonatal sepsis: Early onset sepsis from birth to 7 days is considered.

\section{Statistical analysis}

Data was entered into Excel sheet and SPSS version was used for analysis. Chi-square test was used to find out the association of variables and $\mathrm{p}$ value less than .05 was taken as statistically significant.

\section{RESULTS}

75 antenatals admitted in preterm labour were included in this study. When maternal age was analysed majority were of the age group 26 to 30 years (32 cases).24 women were of the age group 21 to 25 years, 12 belonged to 31 to 35 age group, 6 were less than 20 years and there was one above 35 years.

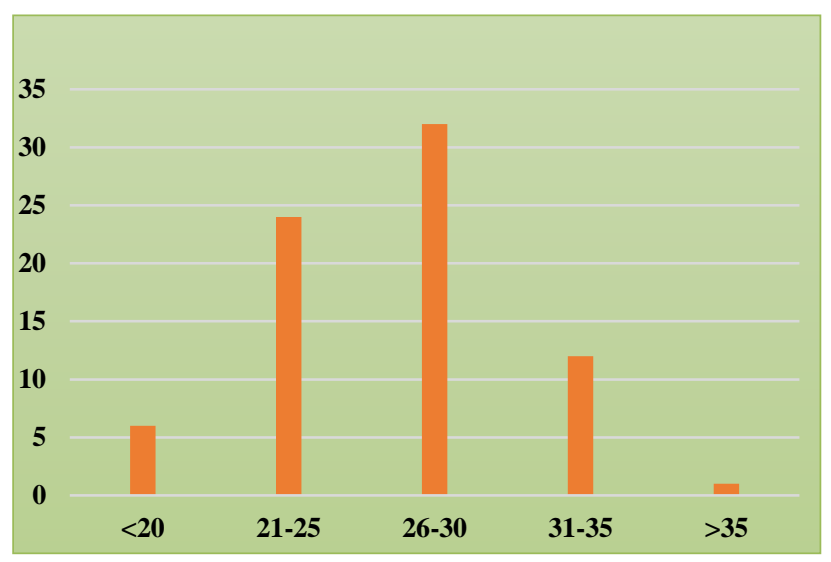

Figure 1: Maternal age distribution. 


\section{Parity}

36 of the subjects were primigravida (48\%), 23 were Para $1(30.6 \%), 5$ multiparas $(6.6 \%)$, and 11 were nullipara $(14.6 \%)$ i.e., women with previous abortions.

Table 1: Distribution of parity.

\begin{tabular}{|lll|}
\hline Obstetric score & Cases & Percentage of women \\
\hline Primigravida & 36 & $48^{*}$ \\
\hline Para1 & 23 & 30.6 \\
\hline Para2 & 5 & 6.6 \\
\hline Para3 & 0 & 0 \\
\hline Nullipara & 11 & 14.6 \\
\hline
\end{tabular}

\section{Gestational age of preterm babies}

Majority of preterm babies in this study belonged to the group of late preterms $(42.6 \%) .25 \%$ of babies were of the gestational age 28 to 32 weeks and $32 \%$ of babies belonged to the group of 32 to 34 weeks.

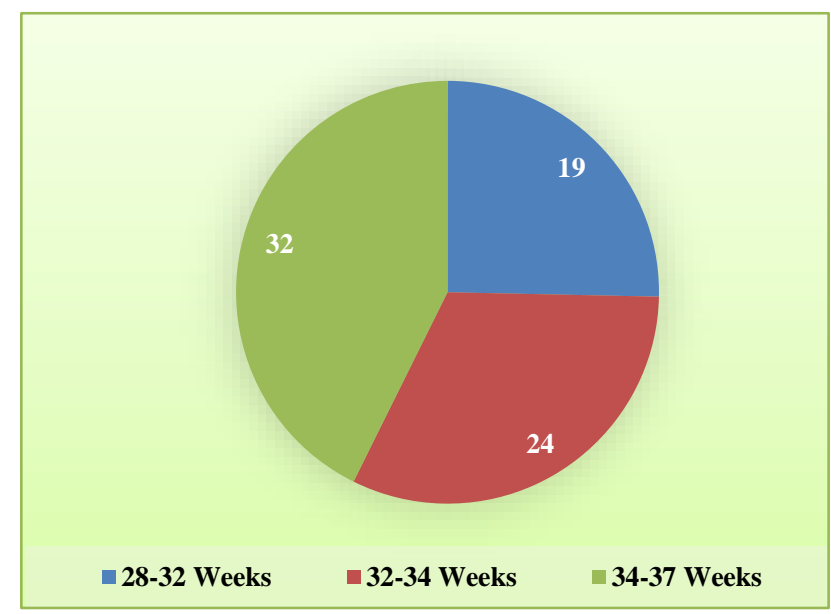

Figure 2: Gestational age distribution (no. of cases).

\section{Risk factors of preterm labour}

PPROM was the major one seen in $57 \%$ i.e., 43 out of 75 cases. This is followed by UTI, 24 cases (32\%) and vaginal infections, $30.7 \%$ of cases. 19 women had past history of abortions and 11 patients $(15 \%)$ had prior history of preterm labour. There were 13 cases of hypertension complicating pregnancy $(17.3 \%)$. Out of the four cases of gestational diabetes $(5 \%)$ three had associated polyhydraminos. 8 of them had Intrauterine growth restriction (10.6\%). Antepartum haemorrhage was reported in 4 cases.

Nineteen women had past history of abortion. Of these 10 had previous one abortion, 7 had previous 2 abortions and 2 of them had previous 3 abortions. $15 \%$ had prior history of preterm labour (11 patients).

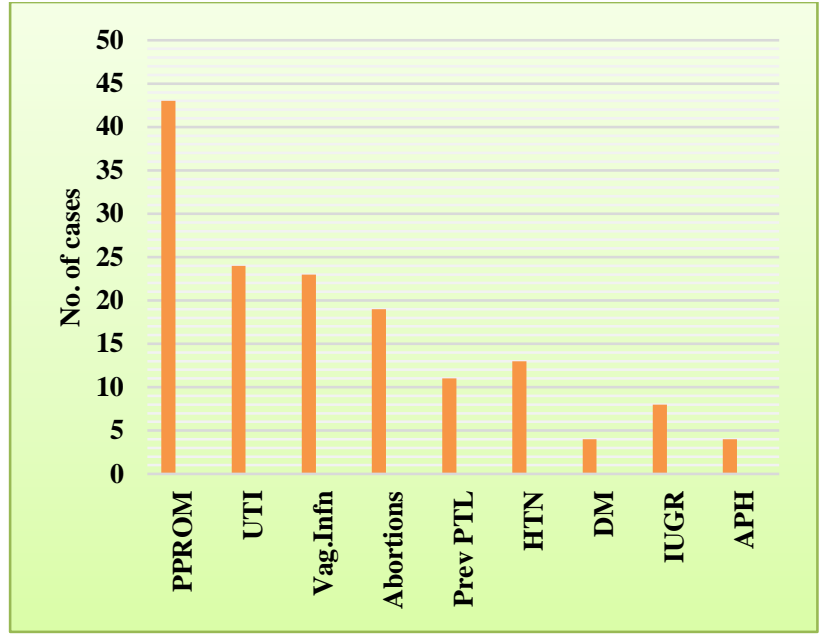

Figure 3: Risk factors of preterm labour.

\section{Risk factors of preterm labour-gestational age wise}

PPROM was the major cause for late preterm labour in this study. 19 women in the late preterm group (59\% of late preterm) had PPROM while 13 in the group 32-34 weeks and 11 among the group 28-32 weeks had PPROM. Vaginal infections were more common in the group 32-34 weeks compared to others. 11 of them had vaginal infection compared to 6 each in the other groups. 5 women with gestational age $32-34$ weeks had past history of preterm delivery compared to 3 each in the other two groups. 19 women had past history of abortions, 9 had in the group 34-37 weeks and 4 in the group 28-32 weeks. Diabetes, hypertension, IUGR, and UTI were common among late preterm group compared to others.

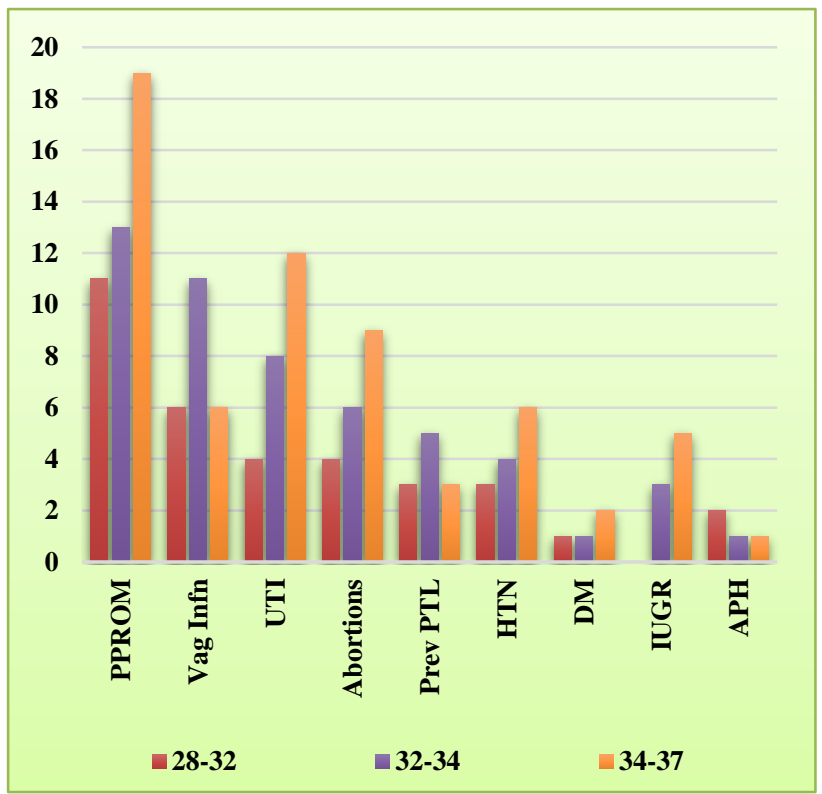

Figure 4: Gestational age wise distribution of risk factors. 


\section{High vaginal swab report}

Among the 75 vaginal swabs $30.7 \%$ was culture positive. E. coli was the most common organism 13 cases (17.3\%). This was followed by Staphylococcus aureus and Kebsiella, 4 cases each (5.3\%). MRSA was reported in 2 cultures. No case of group B haemolytic Streptococcus was reported.

Facilities for isolating Ureaplasma Urealyticum, Mobilincus and Gardnerella was unavailable in present Microbiology department. Negative reports were seen in $69.3 \%$ of cases. This group might have included Mycoplasma, Ureaplasma Urealyticum, Mobilincus and Gardnerella species.

Table 2: High vaginal swab report.

\begin{tabular}{|lll|}
\hline Organism & Number & Percentage \\
\hline E. coli & 13 & $17.3^{*}$ \\
\hline Stap. aureus & 4 & 5.3 \\
\hline MRSA & 2 & 2.6 \\
\hline Klebsiella & 4 & 5.3 \\
\hline Negative & 52 & 69.3 \\
\hline *: E. coli was the most isolated organism in high vaginal swab.
\end{tabular}

\section{Neonatal complications}

The most frequent one was neonatal hyperbilirubinemia, 41 cases $(54.7 \%)$. This was noted to be more severe in the early gestational age group.

Eight out of them needed exchange transfusion and the rest were managed with phototherapy. $23 \%$ of babies had RDS (17cases), of this 11 survived and 6 expired. Culture proven sepsis was seen in 4 babies, but all survived.

Table 3: Neonatal complications.

\begin{tabular}{|lll|l|}
\hline Complication & $\begin{array}{l}\text { Number of } \\
\text { cases }\end{array}$ & \multicolumn{1}{c}{$\begin{array}{l}\text { Percentage of } \\
\text { neonates }\end{array}$} \\
\hline NNHB & 41 & $54.7 *$ & \\
\hline RDS & 17 & 23 & \\
\hline Neonatal sepsis & 4 & 5 & \\
\hline Neonatal death & 7 & 9.86 & \\
*: Neonatal hyperbilirubinaemia & was & the most common \\
neonatal complication. & & & \\
\hline
\end{tabular}

There were 7 neonatal deaths $(9.86 \%), 6$ deaths were due to RDS and the remaining one was an extremely preterm baby. Neonatal hyperbilirubinemia was the leading complication in late preterm group, seen among 17 babies; 16 babies in the group 32-34 weeks had NNHB and 8 among the group 28-32 weeks had NNHB.

RDS was more common among the early preterm 10 cases compared to 4 in the group 32-34 weeks and 3 in the late preterm group. There were 4 cases of neonatal sepsis 2 each in the group 32-34weeks and late preterm group. There were 7 neonatal deaths among these, 4 were of the gestation 32-34 weeks and 3 of the gestation 28-32 weeks. There was no neonatal mortality among the late preterm group.

\section{Correlation between antenatal steroids and RDS}

Corticosteroids are given to all women in the preterm labour (24-36 weeks). Women who delivered at least 24 hours after the initiation of steroid therapy were considered as steroid covered group and those not satisfying this criteria were considered as steroid uncovered group.

When Chi-square test was applied and analysed, the steroid covered group had lesser incidence of RDS with a $p$ value 0.001 which was statistically significant.

Table 4: Correlation between antenatal steroids and RDS.

\begin{tabular}{|llll|}
\hline Steroid & RDS & No RDS & P value \\
Covered & 6 & 49 & $0.001^{*}$ \\
\hline Uncovered & 11 & 8 & \\
\hline
\end{tabular}

*: P value of .001 signifies that antenatal steroids are protective against RDS.

\section{Neonatal survival rate}

There were five babies in the $<1 \mathrm{~kg}$ group, of these 4 were live born and 2 of them survived and thus the survival rate was $50 \% .62 \%$ of the babies in the group 1 to $1.49 \mathrm{~kg}$ survived. The major cause of mortality was RDS. Above $1.5 \mathrm{~kg}$ there was $100 \%$ survival rate provided they tide over neonatal sepsis and NNHB.

Table 5: Neonatal survival rate-birth weight wise.

\begin{tabular}{|lllllll|}
\hline Birth weight & Total & Liveborn & Stillborn & Neonatal death & Survived babies & Neonatal survival rate \\
\hline$<1 \mathrm{~kg}$ & 5 & 4 & 1 & 2 & 2 & $50 \%$ \\
\hline $1-1.49 \mathrm{~kg}$ & 15 & 13 & 2 & 5 & 8 & $62 \%$ \\
\hline $1.5-1.99 \mathrm{~kg}$ & 34 & 33 & 1 & 0 & 33 & $100 \% *$ \\
\hline$>2 \mathrm{~kg}$ & 11 & 11 & 0 & 0 & 11 & $100 \%$ \\
\hline
\end{tabular}

*: Above $1.5 \mathrm{~kg}$ the survival rate was $100 \%$. 
The lowest gestational age at which survival is possible was 29 weeks 2 days in this study and the lowest birth weight for survival in this study was $950 \mathrm{~g}$.

Table 6: Neonatal survival rate-gestational age wise.

\begin{tabular}{|lllll|}
\hline $\begin{array}{l}\text { Gestational } \\
\text { age (weeks) }\end{array}$ & $\begin{array}{l}\text { Live } \\
\text { born }\end{array}$ & IUD & NND & $\begin{array}{l}\text { Survival } \\
\text { rate }\end{array}$ \\
\hline $28-32$ & 17 & 2 & 6 & $64 \%$ \\
\hline $32-34$ & 22 & 2 & 1 & $95 \%$ \\
\hline $34-37$ & 32 & 0 & 0 & $100 \% *$ \\
\hline
\end{tabular}

*: Above 34 weeks there was $100 \%$ survival rate.

\section{DISCUSSION}

Preterm babies have increased short- and long-term morbidity. This study showed majority of preterm babies belonged to the late preterm group $(42.6 \%) .25 \%$ of babies were of the gestational age of 28-32 weeks and $32 \%$ belonged to the group 32 to 34 weeks. A study by Raju and colleagues, conducted in the United States in 2006 showed that $75 \%$ of the babies were late preterm babies. ${ }^{6}$ Another similar study published by National centre for health statistics showed incidence as $70 \% .^{7}$

Analysis of maternal age of the study group showed that $42.6 \%$ of the subjects were of the age group 26 to 30 years. Out of the 75 antenatal cases, $48 \%$ of them were primigravida (36 cases), 23 were second gravida (30.6\%), 5 were multiparas $(6.6 \%)$ and 11 of them were nullipara $(14.6 \%)$ which included women with previous abortions. Majority of them were primigravida, $48 \%$. In a similar study by Ghazi A et al, $40 \%$ of subjects were primigravidas. ${ }^{8}$

Previous obstetric history is an important predictor of preterm labour. 19 women had past history of abortions. Of these ten had previous one abortion, seven had previous two abortions and two of them had previous three abortions. Thus $25.3 \%$ of the study group had past history of one or more abortions. In a study by Singh et al, Lucknow in 2007, $14.4 \%$ of women with preterm labour had past history of abortions. ${ }^{9}$

$15 \%$ of the women in this study had previous preterm labour. According to the study by Hoffman et al having had a single previous preterm increases the risk of subsequent preterm by 4 fold times compared with term. ${ }^{10}$ Although the study by Hewitt and Newham in Australia has reported the incidence of $24 \%$, an Indian study by Singh conducted at Lucknow reported as $14.4 \%$ association. This goes in accordance with present study. $57 \%$ of the patients had PPROM. According to the study conducted by Chan et al in 2001 preterm premature rupture of membranes (PPROM) was associated with two third of cases of preterm labour. ${ }^{11,12}$

Goldenberg et al reported that PPROM causes 30 to $35 \%$ of preterm labour. ${ }^{13}$ According to Parry et al PPROM is responsible for close to $40 \%$ of preterm births. ${ }^{14}$ Thus
PPROM as the major cause for preterm labour in this study goes in accordance with the previous studies.

In present study UTI was reported in $32 \%$ of women .The women presented with symptoms such as increased frequency of micturition and dysuria urine culture was done and a growth of more than $10^{5}$ colony forming unit $/ \mathrm{ml}$ of a single recognised uropathogen was considered significant. ${ }^{15}$ Even if the count is less than this symptomatic women needed treatment because if left untreated most symptomatic women with low counts will show increase in counts $>10^{5} \mathrm{CFU} / \mathrm{ml}$ later. ${ }^{15}$

Twenty-three antenatal women had positive high vaginal swab culture $(30.7 \%)$. As ascending vaginal infection is the most common route for entry of bacteria into amniotic cavity this finding was significant. According to a study by Cassel et al the incidence of subclinical chorioamnionitis was $50 \%$ at 24 to 28 weeks, $30 \%$ at 28 32 weeks, $20 \%$ at 33 to 36 weeks and $10 \%$ after 37 weeks. ${ }^{16}$ Goldenberg also stated that the percentage of positive culture is gestational age dependent and the proportion of positive culture increases with decreasing gestational age. ${ }^{17}$ It is now known that ureaplasma and Mycoplasma are the most common organisms found in intrauterine infections and earlier studies did not culture for these organisms, and hence the rate of positive cultures is much lower than actual rate. ${ }^{18} 40 \%$ of spontaneous preterm labour is attributed to infections. ${ }^{19}$

Genitourinary infection as a cause of preterm labour is a much-studied subject. Gynaecologist can play an important role in the prevention of infection related preterm birth by screening, identifying and treating urinary tract infections and reproductive tract infections.

Early onset neonatal sepsis may occur when the mother has bacterial colonization of urogenital tract. According to McDonald et al bacterial vaginosis organisms and enteropharygeal organisms (mainly E. coli) are associated with preterm labour. ${ }^{20}$

In this study most common organism isolated was E Coli (56\% of total culture positive report). There were four reports of Staphylococcus Aureus and Klebsiella and two cases of MRSA infection. According to Stoll et al GBS is no longer the predominant cause of early onset neonatal sepsis; the honour now goes to E. coli. ${ }^{21}$ In addition the incidence of MRSA infection is increasing (Bratu,2005). ${ }^{22}$

Preterm birth is associated with $75 \%$ of perinatal morbidity and as much as $50 \%$ of long-term neurological handicap. ${ }^{4}$ The most common morbidity found in this study was neonatal hyperbilirubinemia, forty-one cases (57\%). According to literature, jaundice during the first week is seen in about $80 \%$ of preterm babies.

The incidence of RDS in this study was $23 \%$ (17 cases) the incidence of RDS among babies from 32 to 36 weeks 
is $30 \%$ and authors are also getting similar findings. Antenatal administration of steroid has a definite role in reducing the incidence of $\mathrm{RDS}^{23}$ In this study when the incidence of RDS among steroid covered and uncovered were analysed by Chi Square test, $\mathrm{p}$ value is 0.001 and was statistically significant. ${ }^{24}$ Betamethasone is preferred over dexamethasone as the latter causes periventricular leukomalacia. ${ }^{25}$ RDS is the major cause for neonatal mortality in this study. Surfactants are not affordable for the poor and this may account for high mortality due to RDS.

Early onset neonatal sepsis was found among four babies. There was one case each of E Coli, Staphylococcus Aureus, MRSA, and Klebsiella. All four survived. ${ }^{26,27}$ This goes in accordance with the study of Stoll in 2005 who also reported that enterophargyeal organisms are now the leading cause of neonatal sepsis. ${ }^{21}$

After achieving a birth weight of $>1000$ gms or a gestational age of $>28$ weeks (females) and 30 weeks (males), the neonatal survival in developed countries reached $95 \%$. In present study neonates with birth weight above $1.5 \mathrm{~kg}$ had $100 \%$ survival provided they overcome hurdles like RDS, NNHB and neonatal sepsis.

\section{CONCLUSION}

Past history of abortions and previous preterm births are important risk factors. Previous preterm births, especially early preterm births are definitely associated with vaginal infections and there is a role for high vaginal swab culture when they present with threatened preterm labour during this pregnancy. Urinary tract infection and vaginal infections are major risk factors and should be effectively tackled during antenatal visits. There should be no delay in administration of injection Betamethasone as there is a definite reduction in the incidence of RDS when delivery occurs at least 24 hours after the administration of steroids. Neonatal complications are higher even for late preterm births when compared with term, so it is better to induce PPROM after 36 weeks provided there is no chorioamnioitis.

Funding: No funding sources Conflict of interest: None declared

Ethical approval: The study was approved by the Institutional Ethics Committee

\section{REFERENCES}

1. McPheeters ML, Miller WC, Hartmann KE, Savitz DA, Kaufman JS, Garrett JM, et al. The epidemiology of threatened preterm labor: a prospective cohort study. Am J Obstet Gynecol. 2005;192(4):1325-9.

2. Goldenberge RL, Culhane JF, Iams JD, Romero R. Preterm birth 1-epidemiology and causes of preterm birth. Lancet. 2008;371.
3. Ananth CV, Joseph KS, Oyelese Y, Demissie K, Vintzileos AM. Trends in preterm birth and perinatal mortality among singletons: United States, 1989 through 2000. Obstet Gynecol. 2005;105(5):1084-91.

4. McCormick MC. The contribution of low birth weight to infant mortality and childhood morbidity. New Engl J Med.1985;312:82-90.

5. Engle WA. A recommendation for the definition of late preterm (near-term) and the birth weightgestational age classification system. In Seminars in Perinatology. WB Saunders. 2006;(1):2-7.

6. Raju TN, Higgins RD, Stark AR, Leveno KJ. Optimizing care and outcome for late-preterm (nearterm) infants: a summary of the workshop sponsored by the National Institute of Child Health and Human Development. Pediatrics. 2006;118(3):1207-14.

7. March of Dimes Perinatal Data Center Late preterm birth: every week matters. 2005, National Center for Health Statistics, final natality data, January 2008. Available at: www.marchofdimes.com/perstats/.8.

8. Ghazi A, Jabbar S, Siddiq NM. Emrgency obstetric hysterectomy: a lifesaving procedure in obstetrics. Pak J Surg. 2006;22(4):222-6.

9. Uma S, Nisha S, Shikha S. A prospective analysis of etiology and outcome of preterm labor. J Obstet Gynecol India. 2007;57(1):48-52.

10. Hoffman HJ, Bakketeig LS. Risk factors associated with the occurrence of preterm birth. Clin Obstet Gynecol. 1984;27(3):539-52.

11. Chan A, Scott J, Nguyen AM, Sage L, Unit PO, Branch E. Pregnancy outcome in South Australia. Government of South Australia, editor. Pregnancy Outcome (Statistics) Unit SH. Adelaide: Pregnancy Outcome Unit Epidemiology Branch, Department of Human Services. 2007.

12. McParland PC, Bell SC. The fetal membranes and mechanisms underlying their labour associated and pre-labour rupture during pregnancy. Fetal Maternal Med Review. 2004;15:73-108.

13. Goldenberg RL. The management of preterm labour. Obstet Gymecol. 2002;100(5):1020-37.

14. Parry S, Strauss JF. Premature rupture of the fetal membranes. N Eng J Med. 1998;338:663-70.

15. Thomson C. Urinary tract infection. In Warrell DA, Cox TM, Firth J,Benz EJ, eds. Oxford Textbook of Medicine. $4^{\text {th }}$ ed. Oxford University Press; 2003:420433.

16. Cassell G, Hauth J, Andrews W, Cutter G, Goldenberg R. Chorioamnion colonization: correlation with gestational age in women delivered following spontaneous labor versus indicated delivery. Am J Obstet Gynecol. 1993;168(425):A464.

17. Hillier SL, Martius J, Krohn M, Kiviat N, Holmes KK, Eschenbach DA. A case-control study of chorioamnionic infection and histologic chorioamnionitis in prematurity. New Eng J Med. 1988;319(15):972-8.

18. Shim SS, Romero R, Hong JS, Park CW, Jun JK, Kim BI, et al. Clinical significance of intra-amniotic 
inflammation in patients with preterm premature rupture of membranes. Am J Obstet Gynecol. 2004;191(4):1339-45.

19. Geopfert AR, Goldenberg RL. Prediction of prematurity. Curr Opin Obstet Gynecol. 1996;8:417-27.

20. McDonald HM, O'Loughlin JA, Jolly P, Vigneswaran R, Mc Donald PJ. Vaginal infection and preterm labour. BJOG. 1991;98(5):427-35.

21. Stoll BJ, Hansen NI, Higgins RD. Very low birth weight preterm infants with early onset neonatal sepsis:the predominance of gram negative infections continues in the National Institute of Child Health and Human Devolopment Neonatal Research Network, 2002-2003. Pediatr Infect Dis J. 2005;2(7):635-9.

22. Bratu S, Eramo A, Kopec R. Community associated methicillin resisant Staphylococcus aureus in hospital nursery and maternity units. Emerg Infect Dis. 2005;11(6):808-13.

23. Crowther CA, Doyle LW, Haslam RR, Hiller JE, Harding JE, Robinson JS. Outcome at 2 years of age after repeated doses of antenatal corticosteroids. N Eng J Med. 2007;357(12):1179-89.
24. Liggins GC, Howie RN. A controlled trial of antepartum glucocorticoid treatment for prevention of the respiratory distress syndrome in premature infants. Pediatrics. 1972;50(4):515-25.

25. Elimian A, Garry D, Figueroa R, Spitzer A, Wiencek V, Quirk JG. Antenatal betamethasone compared with dexamethasone (betacode trial): a randomized controlled trial. Obstet Gynecol. 2007;110(1):26-30.

26. Kenyon SL, Taylor DJ, Tarnow-Mordi WF. Broadspectrum antibiotics for preterm, prelabour rupture of fetal membranes: the ORACLE I randomised trial. Lancet. 2001;357(9261):979-88.

27. Kenyon S, Pike K, Jones DR, Brocklehurst P, Marlow N, Salt A, et al. Childhood outcomes after prescription of antibiotics to pregnant women with preterm rupture of the membranes: 7-year follow-up of the ORACLE I trial. Lancet. 2008;372(9646):1310-8.

Cite this article as: Mathew SM, Kumar A. A prospective analysis of the risk factors and the perinatal outcome of preterm labour. Int J Reprod Contracept Obstet Gynecol 2018;7:4833-9. 